\title{
Simultaneous determination of caffeine, theobromine and theophylline in foods and pharmaceutical preparations by using ion chromatography
}

\author{
Qing-chuan Chen, Shi-fen Mou*, Xiao-ping Hou, Zhe-ming Ni \\ Research Center for Eco-Environmental Sciences, Academia Sinica, PO Box 2871, Beijing 100085, China
}

Received 19 January 1998; received in revised form 20 April 1998; accepted 28 April 1998

\begin{abstract}
Two ion chromatographic methods have been proposed for the simultaneous determination of caffeine, theobromine and theophylline. The separations were based on isocratic elutions and the determinations on ultraviolet absorbance detections at $274 \mathrm{~nm}$. The detection limits (signal-to-noise ratio 3:1) for the three compounds were all below sub- $\mu \mathrm{g} \mathrm{ml}^{-1}$ level. The methods have been successfully applied to the determination of these three compounds in foods and pharmaceutical preparations, and the average recoveries for various samples ranged from $87 \%$ to $103 \%$. In addition, the retention mechanisms of these three compounds on various ion-exchange resins were discussed. The results obtained revealed that ion-exchange chromatography is possibly a good alternative to conventional liquid chromatography for the separation and determination of some water-soluble, neutral organic molecules with a certain hydrophobicity. (C) 1998 Elsevier Science B.V. All rights reserved.
\end{abstract}

Keywords: Ion chromatography; Caffeine; Theobromine; Theophylline; Food; Pharmaceutical preparation

\section{Introduction}

In recent years, methylxanthine derivatives as a category of alkaloids with distinctive bioactivity have received increasing attention in food and pharmaceutical industries, among which caffeine (CA), theobromine (TB) and theophylline (TP) are probably the most important compounds. Different amounts of caffeine, theobromine and theophylline are natural products in tea, coffee, cacao beans, cola nuts and mate leaves, etc. Caffeine can be used in soft drinks as a flavoring ingredient and recently also in so-called

\footnotetext{
*Corresponding author. Fax: 008610 62923563; e-mail: shifenm@mail.rcees.ac.cn
}

"sports drinks" to increase the basal metabolic rate [1]. They are occasionally components of some overthe-counter pharmaceutical preparations. As a central nervous system stimulant, caffeine can also stimulate the cardiac muscle [2]. Caffeine and theophylline can be used therapeutically to alleviate neonatal apnoea, to control asthmatic manifestations and to relieve bronchial spasms [3,4]. In addition, all of these three alkaloids produce the biological effect of diuresis [3-5]. Excessive intake of these alkaloids will cause many undesired side effects and give rise to symptoms such as tremor, tachycardia and gastro-intestinal difficulties to convulsions, seizures and even death [3-5]. Food is the most important exposure factor to humans for caffeine and theobromine [4,5]. It is considered 
that food can play an important role in methylxanthine toxicity, not only in a direct way by providing large doses of caffeine and theobromine from beverages or chocolate, but also by accelerating the dissolution and absorption rates of theophylline from sustainedrelease theophylline preparations [5]. Therefore, it is very important to determine accurately the contents of these three alkaloids in various foods and pharmaceutical preparations in order to estimate a person's daily intake.

Although a great variety of analytical techniques have been applied to the simultaneous determination of these three alkaloids in various matrices, liquid chromatography (LC) is the most frequently used method nowadays. Most of these procedures were based on reversed-phase (RP) chromatographic separation, particularly with a chemically bonded stationary phase with acetonitrile, methanol or tetrahydrofuran in acetate or phosphate buffer as a mobile phase, and ultraviolet (UV) absorbance detection [618]. Some RPLC methods have been proposed in combination with solid-surface room-temperature phosphorimetric detection [19], mass spectrometric detection [20], and amperometric detection [21]. The separation of the alkaloids could also be accomplished by RP ion-pair or ion-interaction LC [22-25] or micellar LC [26] coupled with UV detection. In this study, two novel methods were proposed for the simultaneous determination of these three alkaloids by using ion chromatography (IC) and applied to the analysis of drinks, tea leaves, roasted coffee, cocoa, injections and tablets with satisfactory results. Both separations were completed within 12 min. Besides, the retention mechanisms of the three alkaloids on various ion-exchange resins were discussed.

\section{Experimental}

\subsection{Apparatus}

A Dionex Model DX-500 ion chromatograph (Sunnyvale, CA, USA) equipped with a $50 \mu 1$ sample loop was employed along with a Dionex PeakNet chromatography workstation for instrument control as well as data acquisition and processing. The detection was carried out by a Dionex AD20 absorbance detector with the detection wavelength set at $274 \mathrm{~nm}$. The cation-exchange separation was achieved by using two Dionex HPIC-CS3 analytical columns which were connected serially and $100 \mathrm{mmol} 1^{-1} \mathrm{HCl}$ was used as an eluent. The anion-exchange separation was achieved by using a Dionex OmniPac PAX-100 analytical column and $15 \mathrm{mmol} \mathrm{1}^{-1} \mathrm{KOH} / 1 \%$ acetonitrile as an eluent. The flow rates of eluents were $1.00 \mathrm{ml} \mathrm{min}^{-1}$. In this study, the peak area measurements were used for all calculations.

\subsection{Reagents}

All solutions were prepared with distilled deionized water and all chemicals were of analytical reagent grade, unless otherwise stated.

Caffeine and theophylline were obtained from the National Institute for the Control of Pharmaceutical and Biological Products (Beijing, China) and theobromine was from Sigma (St. Louis, MO, USA). The stock solutions $\left(0.25 \mathrm{mg} \mathrm{ml}^{-1}\right.$ for theobromine and $0.5 \mathrm{mg} \mathrm{ml}^{-1}$ for caffeine as well as theophylline) were prepared separately by dissolving appropriate amounts of these compounds in water.

\subsection{Preparation of real samples}

All the samples were purchased from local markets, and can be divided into five categories:

1. drinks including two carbonated cola drinks, two canned tea drinks, one sports drink as well as one canned coffee drink,

2. tea leaves,

3. roasted coffee,

4. cocoa, and

5. pharmaceutical preparations including injections and tablets.

The final solutions of all samples were injected into the chromatograph after filtering through a $0.45 \mu \mathrm{m}$ filter.

\subsubsection{Drinks}

A $5.0 \mathrm{ml}$ portion of canned tea drink, or $2.0 \mathrm{ml}$ of canned coffee drink, decarbonated cola drink and sports drink was transferred separately into a $50 \mathrm{ml}$ volumetric flask and diluted to volume with water. 


\subsubsection{Tea leaves, cocoa and roasted coffee}

An accurately weighed amount of ca. $0.5 \mathrm{~g}$ of ground tea leaf, cocoa or roasted coffee ( 70 mesh) was transferred into a $150 \mathrm{ml}$ conical flask, and $80 \mathrm{ml}$ of hot water $\left(80^{\circ} \mathrm{C}\right)$ was added. The solution was heated in a boiling water bath for $60 \mathrm{~min}$ and filtered. The flask was washed with hot water $\left(80^{\circ} \mathrm{C}\right)$ and the resulting solution filtered through the same filter. This step was repeated twice and the filtrates were combined, cooled to room temperature and diluted to $100 \mathrm{ml}$ with water. Further dilutions (1:10 for roasted coffee and 1:20 for tea leaves and cocoa) with water were carried out just before the analysis.

\subsubsection{Pharmaceutical preparations}

An aliquot $(1.0 \mathrm{ml})$ of injection was diluted 100fold with water, and the resulting solution was diluted 25 -fold with water for analysis. A portion $(0.1 \mathrm{~g})$ of a powdered and homogenized tablet was accurately weighed and dissolved with $100 \mathrm{ml}$ water, and $1 \mathrm{ml}$ of this solution was diluted with water in a $100 \mathrm{ml}$ volumetric flask for analysis.

\section{Results and discussion}

From the viewpoint of molecular structures (shown in Fig. 1), the three alkaloids exist mainly as neutral molecules in neutral and weak acidic aqueous solutions, and can be separated by RPLC with acetate or phosphate buffer solution containing an organic solvent. On the other hand, these alkaloids will be converted to cation and anion forms in strong acid and basic solutions, respectively. Hence, from the theoretical point of view, it is possible to separate them by cation-exchange or anion-exchange chromatography under specific elution conditions. The detailed experimental conditions will be discussed separately in the following sections. The columns used in this study were all compatible with $\mathrm{pH} 0-14$ eluents.

\subsection{Cation-exchange chromatography}

In order to maintain these three alkaloids in their cationic form, the acidity of the eluent must be very high. In an earlier study [27], it was found that caffeine could be eluted from a sulfonated cation-exchange resin (Zipax) with $10 \mathrm{mmol}^{-1} \mathrm{HNO}_{3}$ as an eluent. In this study, two Dionex HPIC-CS3 columns packed with sulfonated latex cation-exchange resin [28] were employed as analytical columns, which were serially connected to increase column efficiency, thus obtaining better separation performance.

In cation-exchange chromatography, $\mathrm{HCl}$ was the typical eluent rather than $\mathrm{HNO}_{3}$ because the latter can act as an oxidizing agent. In this study, $\mathrm{HCl}$ was used as an eluent and the effects of the $\mathrm{HCl}$ concentration on the retention behavior of the three alkaloids are summarized in Table 1. We can find that for theophylline, the retention time reaches a maximum when the $\mathrm{HCl}$ concentration was $20 \mathrm{mmol}^{-1}$. For caffeine and theobromine, the retention times are maximum when the eluent concentrations were $100 \mathrm{mmol}^{-1}$ and decrease with further increase in the eluent concentration. An earlier study [27] has found that the retention time of caffeine increased by increasing the eluent $\left(\mathrm{HNO}_{3}\right)$ concentration on a cation-exchange column. This was similar to the results obtained for caffeine in this study when the $\mathrm{HCl}$ concentration ranged from 0.1 to $100 \mathrm{mmol} \mathrm{l}^{-1}$. Unfortunately, the range of the $\mathrm{HNO}_{3}$ concentration in that study [27] was not indicated. In this study, from the viewpoint of resolution,<smiles>Cn1c(=O)c2c(ncn2C)n(C)c1=O</smiles>

Caffeine $\mathrm{pK}_{\mathrm{a}}=14.0, \mathrm{pK}_{\mathrm{b}}=14.2$<smiles>Cn1cnc2c1c(=O)[nH]c(=O)n2C</smiles>

Theobromine $\mathrm{pK}_{\mathrm{a}}=10.0, \mathrm{pK}_{\mathrm{b}}=13.9$<smiles>Cn1c(=O)c2[nH]cnc2n(C)c1=O</smiles>

Theophylline $\mathrm{pK}_{\mathrm{a}}=8.8, \mathrm{pK}_{\mathrm{b}}=13.7$

Fig. 1. The molecular structures and dissociation constants [25] of the three alkaloids. 
Table 1

Effects of the $\mathrm{HCl}$ concentrations on the retention times and resolutions $(R \mathrm{~s})$ of analytes whose concentrations were all $20 \mu \mathrm{g} \mathrm{ml}^{-1}$

\begin{tabular}{|c|c|c|c|c|c|}
\hline \multirow{2}{*}{$\begin{array}{l}\mathrm{HCl} \text { concentration } \\
\left(\mathrm{mmol}^{-1}\right)\end{array}$} & \multicolumn{3}{|c|}{ Retention time (min) } & \multicolumn{2}{|l|}{$R \mathrm{~s}$} \\
\hline & $\mathrm{TB}$ & $\mathrm{TP}$ & $\mathrm{CA}$ & $\mathrm{TB} / \mathrm{TP}$ & $\mathrm{TP} / \mathrm{CA}$ \\
\hline 0.1 & 4.63 & 7.49 & 8.50 & 6.22 & 1.47 \\
\hline 1.0 & 4.62 & 7.48 & 8.51 & 7.72 & 1.67 \\
\hline 5.0 & 4.61 & 7.54 & 8.49 & 7.67 & 1.67 \\
\hline 20.0 & 4.65 & 7.58 & 8.65 & 7.39 & 1.85 \\
\hline 60.0 & 4.70 & 7.42 & 8.74 & 6.80 & 2.20 \\
\hline 100.0 & 4.83 & 7.40 & 9.12 & 6.17 & 2.46 \\
\hline 300.0 & 4.60 & 6.20 & 8.15 & 3.77 & 3.09 \\
\hline 500.0 & 4.33 & 5.35 & 7.12 & 2.55 & 3.33 \\
\hline
\end{tabular}

the optimal concentration of $\mathrm{HCl}$ was $300 \mathrm{mmol}^{-1}$ because it could give satisfactory resolutions between theobromine and theophylline, as well as between theophylline and caffeine. Because in practical applications, the high acidity of the eluent will shorten the usage life of the pump and because the relatively longer retention times for the three alkaloids are helpful to minimize the interferences in real samples which were frequently eluted around void volume, $100 \mathrm{mmol}^{-1} \mathrm{HCl}$ was preferred.

In addition, the effect of an organic modifier such as acetonitrile in the eluent on the retention times of the three alkaloids was studied. The retention times of the alkaloids all decreased by increasing the acetonitrile concentration. Because the addition of an organic modifier could not significantly improve the separation performance, but on the contrary resulted in an increase of the column pressure which caused damage to the analytical columns, finally $100 \mathrm{mmol}^{-1} \mathrm{HCl}$ aqueous solution was chosen as the eluent.

Similar to all RPLC procedures [6-26], in this study, these three alkaloids were eluted from the cation-exchange separation columns in the sequence theobromine, theophylline and caffeine, which was consistent with the order of hydrophobicity. In principle, it is well known that apart from pure ionexchange processes, non-ionic interactions (mainly adsorption) between the ion-exchange resin and the non-ionized neutral molecule along with all polarizable ions do exist [29]. As a result, we think that the three alkaloids were retained on the cation-exchange resin by both ion-exchange and adsorption interac- tions. In the acidity range studied, the dominant form of the three alkaloids should be the neutral molecules. Additionally, by increasing the eluent $(\mathrm{HCl})$ concentration, at least three kinds of changes occurred that were all probably related to the retention behavior of the three alkaloids:

1. the increase of cationic species resulted in the enhancement of cation-exchange interaction between the alkaloids and resin, which also possibly caused an increase of the retention times;

2. the increase of the $\mathrm{HCl}$ concentration resulted in an increase of the elution strength for cations, which also caused the decrease of the retention times of the alkaloids; and

3. the increase of the eluent acidity suppressed the dissociation of sulfonated functional groups, which caused a decrease of the available cation-exchange sites on the column and led to a reduction of the retention times of the alkaloids.

Among them, the effects of the first and the other two changes were contrary to the retention times of the alkaloids. When the eluent concentration varied in the low concentration range, the first effect was dominant, while in the high concentration range, the other two effects were dominant. So, a maximum retention time for each alkaloid should be observed when the eluent concentration varied, and the eluent concentration at which the maximum retention time occurred for theophylline should be the lowest because its $\mathrm{p} K_{\mathrm{b}}$ value was the lowest. All these assumptions were confirmed by the experimental results shown in Table 1. From this point, the cation-exchange interaction of the alkaloids with the stationary phase can be proved as well.

\subsection{Anion-exchange chromatography}

From the viewpoint of dissociation constants, it was relatively easy to maintain theobromine and theophylline in their anionic form in anion-exchange chromatography, and the relatively distinct differences between the $\mathrm{p} K_{\mathrm{a}}$ values may be an advantageous factor for anion-exchange separation. In the typical concentration of eluents in anion-exchange chromatography including hydroxide and carbonate aqueous solution, the dominant existing forms were neutral molecules 
for caffeine and anions for theobromine as well as theophylline, respectively. Therefore, it was vital to select one kind of anion-exchange separation column, which also possessed relatively strong hydrophobicity to retain caffeine, for the simultaneous determination of these three alkaloids.

In the first place, the most commonly used anionexchange separation column Dionex IonPac AS4ASC with medium hydrophobicity [30] was tried, and $\mathrm{KOH}$ solution was selected as an eluent. The results showed that caffeine, theobromine and theophylline were sequentially eluted, and the retention times of theobromine and theophylline decreased when the $\mathrm{KOH}$ concentration increased from 2.5 to $100 \mathrm{mmol}^{-1}$. Under these elution conditions, caffeine was eluted at the void time, which indicated that caffeine existed as neutral molecules which are not retained on this anion-exchange separation column at all. When the concentration of $\mathrm{KOH}$ was increased up to $500 \mathrm{mmol} \mathrm{l}^{-1}$, caffeine and theobromine were coeluted after the void volume, which indicated that anion-exchange processes between caffeine and resin occurred under this condition. The retention times of all alkaloids were decreased with further increase in the eluent concentration and this made it impossible to separate one from the other. All these results revealed that the use of a column with stronger hydrophobicity would be a better solution to the simultaneous determination of these three alkaloids in anion-exchange chromatography. So, a Dionex OmniPac PAX-100 analytical column with stronger hydrophobicity was chosen. For this column, in order to wet the hydrophobic substrate and to maintain the maximum column performance, it is necessary that the eluent always has minimally $1 \%$ organic solvent such as acetonitrile [31]. Hence, the effects of the $\mathrm{KOH}$ concentration in $1 \%$ acetonitrile solution on the retention behavior of the three alkaloids were studied and the results are shown in Table 2. The three alkaloids were eluted after the void volume in the same sequence just like the results obtained on an IonPac AS4A-SC column, and the retention times of theobromine as well as theophylline were decreased by increasing the $\mathrm{KOH}$ concentration in the range $10-300 \mathrm{mmol}^{-1}$, while the retention time of caffeine remained constant, which also revealed that caffeine was retained by the mechanism of adsorption, and no anion-exchange interaction did occur under these elution conditions.
Table 2

\begin{tabular}{|c|c|c|c|c|c|}
\hline \multirow{2}{*}{$\begin{array}{l}\text { KOH concentration } \\
\left(\mathrm{mmol} \mathrm{l}^{-1}\right)\end{array}$} & \multicolumn{3}{|c|}{ Retention time (min) } & \multicolumn{2}{|l|}{$R \mathrm{~s}$} \\
\hline & $\mathrm{CA}$ & TB & $\mathrm{TP}$ & $\mathrm{CA} / \mathrm{TB}$ & $\mathrm{TB} / \mathrm{TP}$ \\
\hline 10 & 1.44 & 2.26 & 9.09 & 4.12 & 9.10 \\
\hline 15 & 1.43 & 2.06 & 7.62 & 3.24 & 8.62 \\
\hline 20 & 1.43 & 1.92 & 6.64 & 2.62 & 8.24 \\
\hline 25 & 1.43 & 1.83 & 6.02 & 2.16 & 7.94 \\
\hline 30 & 1.43 & 1.78 & 5.56 & 1.82 & 7.74 \\
\hline 35 & 1.43 & 1.72 & 5.14 & 1.53 & 7.51 \\
\hline 40 & 1.43 & 1.67 & 4.81 & 1.96 & 7.32 \\
\hline 100 & 1.41 & 1.46 & 2.68 & & \\
\hline 300 & 1.43 & 1.38 & 1.92 & & \\
\hline 500 & 1.46 & 1.36 & 1.77 & & \\
\hline 700 & 1.44 & 1.34 & 1.68 & & \\
\hline
\end{tabular}

Effects of the $\mathrm{KOH}$ concentrations in $1 \%$ acetonitrile on the retention times and resolutions $(R \mathrm{~s})$ of analytes whose concentrations were all $20 \mu \mathrm{g} \mathrm{ml}^{-1}$

However, we can assume that by further increase of the $\mathrm{KOH}$ concentration, caffeine will be converted from neutral molecules to anions which will be retained by anion-exchange interaction resulting in an increase of the retention time. When the $\mathrm{KOH}$ concentration is increased further, i.e., the elution ability for anions is stronger, the retention time of caffeine will decrease. This assumption was also confirmed by the results listed in Table 2. Besides, we can also find that the elution sequence changes when the concentration of $\mathrm{KOH}$ was more than $300 \mathrm{mmol}^{-1}$, i.e., theobromine that exists completely in the form of anions is eluted before caffeine that exists simultaneously in the form of neutral molecules and anions. Under these conditions, the retention mechanisms for these alkaloids should include both adsorption and anion-exchange interactions. In principle, the anion-exchange interactions of theobromine and theophylline with a stationary phase should be stronger than that of caffeine because the dominant forms of theobromine and theophylline are anions while the dominant form of caffeine is a neutral molecule in the $\mathrm{pH}$ range of the eluent studied. However, the hydrophobicity of caffeine was the strongest, and that of theobromine was the weakest. Hence, a compromise between the two interactions was accomplished which was shown in the elution sequence we observed in this $\mathrm{pH}$ range: theobromine, caffeine and theophylline. From the viewpoint of separation, if the concentration of $\mathrm{KOH}$ was too low, the run time would 
be unnecessarily prolonged and the peak of theophylline would be tailing; if the concentration of $\mathrm{KOH}$ was too high, the resolutions for these alkaloids would not be satisfactory. Probably a gradient elution would be a better solution, but at least $10 \mathrm{~min}$ equilibration time between runs will be needed and repeatabilities for retention times and quantifications will be poorer, all of which are disadvantageous for routine analysis. Taking all the factors into account, an isocratic elution procedure was adopted. Finally, $15 \mathrm{mmol}^{-1}$ was selected as the suitable concentration of the $\mathrm{KOH}$ solution.

Furthermore, the effect of the acetonitrile concentration on the retention times of these alkaloids was studied. By increasing the organic solvent concentration, the retention times of the alkaloids were all decreased. Because the separation performance was not apparently changed when the acetonitrile concentration varied from $1 \%$ to $2.5 \%$, and the high concentration of acetonitrile caused an increased column pressure and the peak of caffeine would be very near to negative water peak resulting in an inaccurate quantification result, finally, $15 \mathrm{mmol}^{-1} \mathrm{KOH} / 1 \%$ acetonitrile was chosen.

Moreover, further studies of the retention mechanisms of the three alkaloids on the two anion-exchange separation columns with alkanol quaternary ammonium as functional groups were carried out. We think that anion-exchange and adsorption interactions with a stationary phase exist simultaneously for theobromine and theophylline under the elution conditions as above mentioned, and for caffeine in high $\mathrm{pH}$ ranges. While in relatively low $\mathrm{pH}$ ranges, only adsorption interaction occurred between resin and caffeine, which were predominantly present as neutral molecules. If this kind of interaction is inadequately strong, caffeine would be eluted at the void time, just as the results obtained by using the IonPac AS4A-SC column; on the contrary, caffeine would be retained, just like the results obtained by using OmniPac PAX-100 column. By increasing the $\mathrm{KOH}$ concentration in the eluent to obtain a conversion to anions for these three alkaloids, under these conditions, some changes might occur similar to those observed in cation-exchange chromatography, i.e.:

1. the increase of anionic species results in the enhancement of the anion-exchange interaction between the alkaloids and resin, which also causes an increase of the retention times;

2. the increase of the $\mathrm{KOH}$ concentration in the eluent results in an increase of the elution strength for anions, which also causes a decrease of the retention times; and

3. the increase of basicity of the eluent suppresses the dissociation of the quaternary ammonium groups, which causes a decrease of the available anionexchange sites on the column, and a reduction of the retention times.

Therefore, just like the results obtained in cationexchange chromatography, a maximum retention time for each alkaloid should be observed by varying the $\mathrm{KOH}$ concentration in the eluent. According to $\mathrm{p} K_{\mathrm{a}}$ values, it could be estimated that the concentrations at which the maximum retention time occurs were the highest for caffeine, and the lowest for theophylline. This concentration value for caffeine is shown in Table 2, and that for theobromine was found to be $0.5 \mathrm{mmol} \mathrm{l}^{-1} \mathrm{KOH} / 1 \%$ acetonitrile. Because the $\mathrm{p} K_{\mathrm{a}}$ value of theophylline was near to 7 and the neutral eluent resulted in very high column pressure, that concentration value for theophylline was not found. Nevertheless, basically our main assumptions were confirmed.

After all, either cation-exchange or anion-exchange chromatography could provide a good separation for the three alkaloids, and this conclusion suggested that they could be possibly used for the analysis of other alkaloids. It also revealed that ion-exchange chromatography is possibly a good solution for the separation and determination of some water-soluble, neutral organic molecules with a certain hydrophobicity by using a strong acid or basic eluent to convert the neutral analytes to cations or anions. Because the contents of caffeine and theobromine were higher than that of theophylline in the majority of foods, the elution sequence in cation-exchange chromatography aided in obtaining more accurate quantification results. Cation-exchange chromatography should be more suitable for the routine analysis and anionexchange chromatography could be an alternative. In this study, the former was used for real samples analysis and the latter was employed for comparison. 
Table 3

Linearities and detection limits for analytes

\begin{tabular}{llllll}
\hline Method & Analyte & $\begin{array}{l}\text { Concentration } \\
\text { range }\left(\mu \mathrm{g} \mathrm{ml}^{-1}\right)\end{array}$ & Regression equation ${ }^{\mathrm{a}}$ & $\begin{array}{l}\text { Correlation } \\
\text { coefficient }(n=5)\end{array}$ & $\begin{array}{l}\text { Detection limit } \\
\left.(\mu \mathrm{g} \mathrm{ml})^{-1}\right)\end{array}$ \\
\hline Cation-exchange & TB & $0.1-20$ & $A=(1.86 c-0.03) \times 10^{5}$ & 0.9999 & 0.03 \\
& TP & $0.1-20$ & $A=(2.05 c-0.05) \times 10^{5}$ & 0.9999 & 0.06 \\
& CA & $0.1-20$ & $A=(1.76 c-0.09) \times 10^{5}$ & 0.9998 & 0.1 \\
Anion-exchange & TB & $0.1-20$ & $A=(1.99 c+0.26) \times 10^{5}$ & 0.9998 & 0.03 \\
& TP & $0.2-20$ & $A=(2.44 c-0.19) \times 10^{5}$ & 0.9999 & 0.2 \\
& CA & $0.1-20$ & $A=(1.51 c+0.39) \times 10^{5}$ & 0.9999 & 0.06 \\
\hline
\end{tabular}

${ }^{\mathrm{a}} A=$ Peak area (arbitrary unit), $c=$ concentration of analytes $\left(\mu \mathrm{g} \mathrm{ml}^{-1}\right)$.

\subsection{Selection of detection wavelength}

Although several novel detection modes [19-21] have been proposed recently, UV detection was still the first choice in the LC analysis of these alkaloids [6-18,22-26] due to its simplicity and reliability. In the two separation modes, the maximum absorption wavelengths are all $274 \mathrm{~nm}$ for the three alkaloids, which facilitated the simultaneous determination of all the analytes. Moreover, the absorption curves of each analyte in the two separation modes are different, which also gives an evidence for the different existing forms for the three alkaloids in different eluents. The background absorbances of eluents in the two methods were very low at $274 \mathrm{~nm}$, so $274 \mathrm{~nm}$ was chosen for further studies.

\subsection{Analytical characteristics}

Under the optimized experimental conditions of both methods, all three alkaloids showed good linearities between the concentrations and peak areas. The detection limits $(S / N=3)$ were calculated as well. All the results are shown in Table 3. The precisions were evaluated by performing seven replicate analyses of two concentration levels of mixed standard solutions, and the results are summarized in Table 4. It can be seen that the precisions in cation-exchange chromatography are the best.

\subsection{Analysis of real samples}

Recently, Moriyasu et al. [32] reported the contents of caffeine, theobromine and theophylline in Japanese
Table 4

Precisions for analytes

\begin{tabular}{lclll}
\hline Method & $\begin{array}{l}\text { Concentration } \\
\text { level }\left(\mu \mathrm{g} \mathrm{ml}^{-1}\right)\end{array}$ & \multicolumn{2}{l}{$\begin{array}{l}\text { Relative standard deviation } \\
(\%, n=7)\end{array}$} \\
\cline { 3 - 5 } & & $\mathrm{TB}$ & $\mathrm{TP}$ & $\mathrm{CA}$ \\
\hline Cation-exchange & 5 & 0.73 & 0.59 & 0.70 \\
& 20 & 0.38 & 0.34 & 0.36 \\
& & & & \\
Anion-exchange & 5 & 0.76 & 1.91 & 1.12 \\
& 20 & 0.44 & 0.69 & 0.35 \\
\hline
\end{tabular}

foods. In this study, a preliminary investigation on the contents of these alkaloids in 14 kinds of Chinese foods was carried out. All foods were divided into four categories, among which tea leaf was selected as the most important one. The global production of tea has increased by an average annual rate of $3.0 \%$ over the last three decades [33]. To date, China is the second producer and exporter of tea in the world [34], and has experienced an increase in consumption for the period 1979-1993 of 5.2\% annually [35]. In general, Chinese tea can be divided into six categories: green tea, black tea, oolong tea, dark green tea, white tea and yellow tea [36]. One representative sample for each category of tea leaf was selected for analysis. In addition, several commonly used pharmaceutical preparations including injections and tablets were employed for assay. The results of all samples are shown in Table 5, and the chromatograms are presented in Figs. 2 and 3. From the results listed in Table 5 and the spike recovery results listed in Table 6, we can see that on the whole cation-exchange chromatography is advantageous for obtaining more precise and accurate 
Table 5

Analysis of real samples

\begin{tabular}{|c|c|c|c|c|c|c|}
\hline \multirow[t]{3}{*}{ Sample } & \multicolumn{6}{|c|}{ Content $^{\mathrm{a}}\left(\mu \mathrm{g} \mathrm{ml}^{-1}, \mathrm{mg} \mathrm{ml}^{-1}\right.$ or $\left.\mathrm{mg} \mathrm{g}^{-1}\right)$} \\
\hline & \multicolumn{3}{|c|}{ Cation-exchange method } & \multicolumn{3}{|c|}{ Anion-exchange method } \\
\hline & $\overline{\mathrm{CA}}$ & TB & $\mathrm{TP}$ & $\overline{\mathrm{CA}}$ & TB & $\mathrm{TP}$ \\
\hline$\overline{\text { Cola A }}$ & $100.0 \pm 0.4$ & $\mathrm{ND}^{\mathrm{b}}$ & ND & $99.0 \pm 0.6$ & ND & ND \\
\hline Cola B & $89.2 \pm 0.2$ & ND & ND & & & \\
\hline Tea drink A & $45.0 \pm 0.3$ & $1.63 \pm 0.05$ & ND & & & \\
\hline Tea drink B & $158 \pm 2$ & $2.83 \pm 0.05$ & ND & & & \\
\hline Sports drink & $184 \pm 2$ & ND & ND & & & \\
\hline Coffee drink & $219 \pm 4$ & ND & ND & & & \\
\hline Roasted coffee & $15.16 \pm 0.42$ & $0.32 \pm 0.04$ & ND & $15.70 \pm 0.44$ & $0.31 \pm 0.03$ & ND \\
\hline Cocoa & $1.36 \pm 0.05$ & $19.41 \pm 0.25$ & ND & $1.46 \pm 0.06$ & $19.12 \pm 0.18$ & ND \\
\hline \multicolumn{7}{|l|}{ Tea leaf } \\
\hline Longjing green tea (green tea) & $23.89 \pm 0.44$ & $1.81 \pm 0.07$ & ND & $23.98 \pm 0.47$ & $1.83 \pm 0.07$ & ND \\
\hline Yunnan black tea (black tea) & $33.85 \pm 0.52$ & $1.69 \pm 0.05$ & ND & & & \\
\hline Tieguanyin (oolong tea) & $22.04 \pm 0.44$ & $0.49 \pm 0.03$ & ND & & & \\
\hline Puer square tea (dark green tea) & $36.67 \pm 0.84$ & $3.02 \pm 0.11$ & ND & & & \\
\hline Baimudan (white tea) & $28.42 \pm 0.87$ & $0.96 \pm 0.05$ & ND & & & \\
\hline Junshan silvery tip (yellow tea) & $30.78 \pm 0.72$ & $2.29 \pm 0.07$ & ND & & & \\
\hline \multicolumn{7}{|l|}{ Pharmaceutical preparation } \\
\hline Aminophylline injection & ND & ND & $16.75 \pm 0.14$ & ND & ND & $16.75 \pm 0.25$ \\
\hline Aminophylline tablet & ND & ND & $616.0 \pm 3.3$ & & & \\
\hline Caffeine and sodium benzoate tablet & $438.0 \pm 5.8$ & ND & ND & & & \\
\hline
\end{tabular}

${ }^{\mathrm{a}}$ Mean \pm standard deviation $(n=4), \mu \mathrm{g} \mathrm{ml}^{-1}$ for drinks, $\mathrm{mg} \mathrm{ml}^{-1}$ for injections and $\mathrm{mg} \mathrm{g}^{-1}$ for the other samples.

${ }^{\mathrm{b}} \mathrm{ND}=$ not detected.

Table 6

Results of spike recoveries

\begin{tabular}{|c|c|c|c|c|c|c|c|c|c|}
\hline \multirow[t]{3}{*}{ Sample } & \multicolumn{3}{|c|}{$\operatorname{Added}^{\mathrm{a}}\left(\mathrm{mg} \mathrm{ml}^{-1}\right.$ or $\left.\mathrm{mg} \mathrm{g}^{-1}\right)$} & \multicolumn{6}{|c|}{ Recovery $^{\mathrm{b}}(\%)$} \\
\hline & \multirow[t]{2}{*}{ CA } & \multirow[t]{2}{*}{$\mathrm{TB}$} & \multirow[t]{2}{*}{$\mathrm{TP}$} & \multicolumn{3}{|c|}{ Cation-exchange } & \multicolumn{3}{|c|}{ Anion-exchange } \\
\hline & & & & $\overline{\mathrm{CA}}$ & TB & $\mathrm{TP}$ & $\overline{\mathrm{CA}}$ & TB & TP \\
\hline$\overline{\text { Cola A }}$ & 0.1 & 0.1 & 0.1 & $99.5 \pm 1.0$ & $97.8 \pm 0.4$ & $98.0 \pm 0.9$ & $96.2 \pm 1.2$ & $94.8 \pm 0.6$ & $95.0 \pm 2.3$ \\
\hline Longjing green tea & 20 & 2 & 2 & $96.7 \pm 1.9$ & $90.0 \pm 2.7$ & $90.4 \pm 3.5$ & $95.5 \pm 1.1$ & $87.4 \pm 3.7$ & $88.6 \pm 4.0$ \\
\hline Roasted coffee & 20 & 2 & 2 & $96.3 \pm 2.0$ & $94.5 \pm 3.2$ & $95.6 \pm 4.2$ & $89.2 \pm 1.2$ & $99.4 \pm 5.5$ & $93.0 \pm 4.9$ \\
\hline Cocoa & 2 & 20 & 2 & $96.7 \pm 2.0$ & $89.4 \pm 1.1$ & $93.5 \pm 2.4$ & $91.8 \pm 3.9$ & $90.6 \pm 1.8$ & $92.0 \pm 5.0$ \\
\hline Aminophylline injection & 15 & 15 & 15 & $98.7 \pm 0.7$ & $99.7 \pm 0.6$ & $102.3 \pm 1.1$ & $96.2 \pm 0.4$ & $99.1 \pm 0.5$ & $101.7 \pm 1.6$ \\
\hline
\end{tabular}

${ }^{\mathrm{a}}$ Added level, $\mathrm{mg} \mathrm{ml}^{-1}$ for liquid samples and $\mathrm{mg} \mathrm{g}^{-1}$ for solid samples.

${ }^{\mathrm{b}}$ Mean \pm standard deviation $(n=5)$.

results. It can be concluded that for routine analysis of real samples, cation-exchange chromatography was preferred and anion-exchange chromatography could be used as an alternative.

\section{Acknowledgements}

The authors wish to thank the Dionex Corporation for financial support. 
(a)

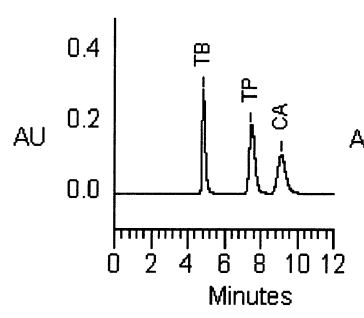

(c)

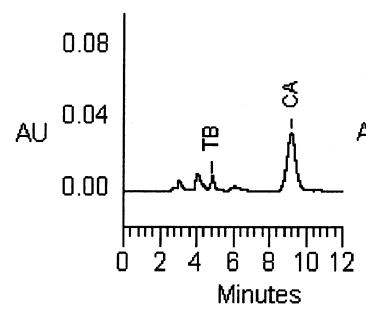

(e)

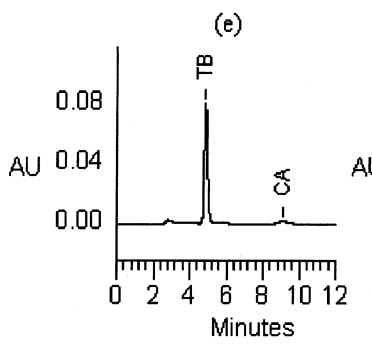

Fig. 2. Chromatograms of standard solution where the concentrations of all analytes were $20 \mu \mathrm{g} \mathrm{ml}^{-1}$ (a) and the diluted solutions of real samples in cation-exchange chromatography; (b) cola A; (c) longjing green tea leaf; (d) roasted coffee; (e) cocoa; (f) aminophylline injection. The experimental conditions were described in the text.

\section{References}

[1] M.A. Ford, in: P.R. Ashurst (Ed.), Production and Packaging of Non-Carbonated Fruit Juices and Fruit Beverages, Blackie Academic and Professional, London, 1995, pp. 310-330.

[2] A.H. Varnam, J.P. Sutherland, Beverages: Technology, Chemistry and Microbiology, Chapman \& Hall, London, 1994, p. 234.

[3] B. Stavric, Food Chem. Toxicol. 26 (1988) 541.

[4] B. Stavric, Food Chem. Toxicol. 26 (1988) 645.

[5] B. Stavric, Food Chem. Toxicol. 26 (1988) 725.

[6] H. Terada, Y. Sakabe, J. Chromatogr. 291 (1984) 453.

[7] W.J. Hurst, K.P. Snyder, R.A. Martin Jr., , J. Chromatogr. 318 (1985) 408

[8] K. Fukuhara, Y. Matsuki, T. Nanbara, Shokuhin Eiseigaku Zasshi 26 (1985) 208. (a)

(b)
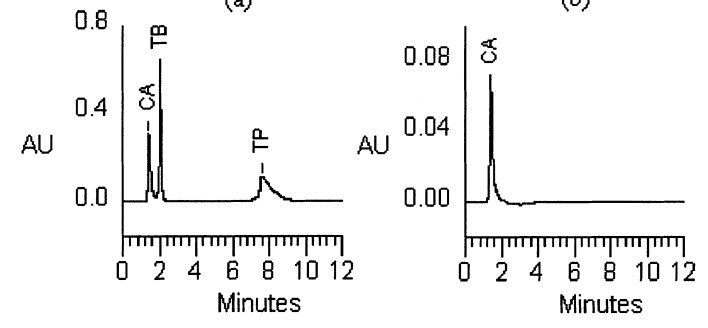

(c)
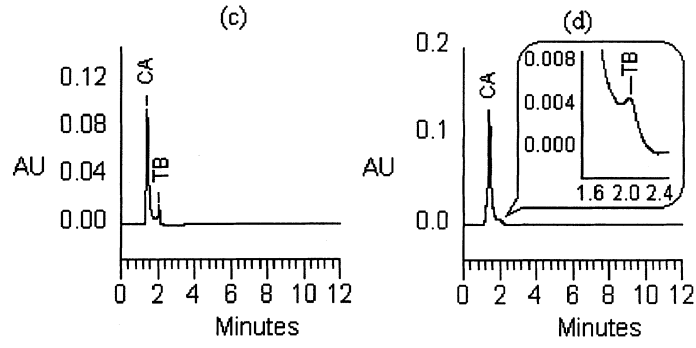

(e)

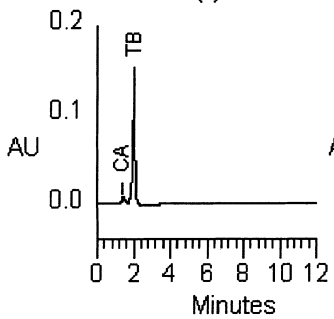

(f)

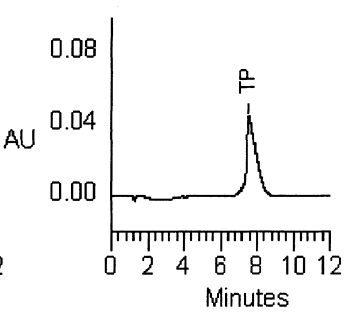

Fig. 3. Chromatograms of standard solution where the concentrations of all analytes were $20 \mu \mathrm{g} \mathrm{ml}^{-1}$ and the diluted solutions of real samples in anion-exchange chromatography. The labels of the figures are the same as in Fig. 2. The experimental conditions were described in the text.

[9] K. Nakazawa, H. Tanaka, Yakugaku Zasshi 105 (1985) 848.

[10] N. Grgurinovich, J. Chromatogr. 380 (1986) 431.

[11] M.F. Vergnes, J. Alary, Talanta 33 (1986) 997.

[12] J. Haginaka, J. Wakai, H. Yasuda, Y. Kimura, J. Chromatogr. 529 (1990) 455.

[13] S.C. Liu, Yaowu Fenxi Zazhi 11 (1991) 7.

[14] P. Parra, A. Limon, S. Ferre, T. Guix, F. Jane, J. Chromatogr. 570 (1991) 185.

[15] M.A. Abuirjeie, M.S. El-Din, I.I. Mahmoud, J. Liq. Chromatogr. 15 (1992) 101.

[16] Y.S. Huang, Z.S. Liu, H. Lu, Y.Q. Sun, Yaowu Fenxi Zazhi 12 (1992) 28.

[17] H. Terada, A. Suzuki, H. Tanaka, K. Yamamoto, Shokuhin Eiseigaku Zasshi 33 (1992) 347.

[18] T. Moriyasu, K. Saito, M. Nakazato, F. Ishikawa, K. Fujinuma, T. Nishima, Y. Tamura, Shokuhin Eiseigaku Zasshi 37 (1996) 14. 
[19] A.D. Campiglia, J.J. Laserna, A. Berthod, J.D. Winefordner, Anal. Chim. Acta 244 (1991) 215.

[20] Y. Hieda, S. Kashimura, K. Hara, M. Kageura, J. Chromatogr. B 667 (1995) 241.

[21] A. Meyer, T. Ngiruwonsanga, G. Henze, Fresenius' J. Anal. Chem. 356 (1996) 284.

[22] J.J. Lauff, J. Chromatogr. 417 (1987) 99.

[23] J. Blanchard, C.W. Weber, L.-E. Shearer, J. Chromatogr. Sci. 28 (1990) 640.

[24] M.C. Gennaro, C. Abrigo, Fresenius' J. Anal. Chem. 343 (1992) 523

[25] M.C. Gennaro, C. Abrigo, P. Biglino, Analyst 117 (1992) 1071.

[26] I. Pérez-Martínez, S. Sagrado, M.J. Medina-Hernández, Anal. Chim. Acta 304 (1995) 195.

[27] B.L. Madison, W.J. Kozarek, C.P. Damo, J. Assoc. Off. Anal. Chem. 59 (1976) 1258.

[28] M.E. Potts, J.R. Stillian, J. Chromatogr. Sci. 26 (1988) 315.
[29] J. Weiss, Ion Chromatography, VCH, Weinheim, 1995, p. 27.

[30] Dionex Product Selection Guide 1991, Dionex Corporation, Sunnyvale, CA, 1991.

[31] Installation Instructions and Troubleshooting Guide for the OmniPac PAX-100 Analytical Column, Dionex Corporation, Sunnyvale, CA, 1991.

[32] T. Moriyasu, K. Saito, M. Nakazato, F. Ishikawa, K. Fujinuma, T. Nishima, Y. Tamura, Shokuhin Eiseigaku Zasshi 37 (1996) 59.

[33] S. Taylor, I. McDowell, in: R. Macrae, R.K. Robinson, M.J. Sadler (Eds.), Encyclopaedia of Food Science Food Technology and Nutrition, Academic Press, London, 1993, pp. 45234526.

[34] X.D. Cai, Chaye Kexue 16 (1996) 18.

[35] L.J. Zhan, Chaye Tongbao 18 (1996) 1.

[36] T.H. Zhang, Tea Science Dictionary of China, Shanghai Science and Technology Press, Shanghai, 1995, p. 172. 